\title{
The Aged Radio Body: Corporeality and Old Age in All That Fall
}

\section{Born old: Samuel Beckett and old age}

Anyone familiar with the sheer quantity and quality of research on Samuel Beckett and his work might be excused for thinking that Beckett studies could serve as a barometer for the Zeitgeist of literary criticism in general. That certainly seems to be the case as far as the thematisation of old age is concerned: the prevalence of that theme in Beckett's oeuvre is undeniable (Barry, 2016, 206), especially in his later writings (Gilleard, 2016; Groninger and Childress, 2007, 262; Hubert, 2005, 45), and yet far too little has been written on its importance in Beckett's artistic practice and indeed personal philosophy. After all, he was fascinated with the idea of being prematurely old (White, 2009, 26), and, as Elizabeth Barry points out, 'Beckett seemed to appropriate the [aged] condition as spiritually his own. He said as much' $(2016,206)$.

Unfortunately, even when that theme is brought to the fore (which happens more seldom than it should), it does not always elicit readings that do justice to the knottiness of the concept of old age - which Beckett was clearly alive to. For instance, when Emily Bloom briefly alludes to 'the emphasis on elderly characters who dominate so many of Beckett's works', she takes it to signify, as do many other critics, 'that there is no solace to be found in this ageing world through the promise of regeneration' $(2016,144)$. A starker example of this is Kathryn White's claim that 'Beckett's representation of the aged is a horrific study of the implications of growing old and the undesirability of reaching those twilight years, when all we have to look forward to is bad health, isolation and the overwhelming need to reach the grave' $(2009,22)$. The picture White paints may be relentlessly bleak, but it can also be perceived as an unusually emphatic expression of what many commentators routinely take Beckett's main thrust to be as far as ageing is concerned.

Other approaches to old age in Beckett include examples of 'literary gerontology', which may or may not be animated by an anti-ageist sentiment (see Groninger and Childress, 2007); biographical readings that seem to favour, and even be defined by, the 'late style' approach (Adelman, 2005; Gilleard, 2016); and political readings of Beckett's resistance against 'inhumanity' (Kennedy, 2018, 2). Specialised interpretations such as these are certainly valuable within the right context, but they are not always particularly alert to either the subtlety that the ambiguous, contradictory, almost indefinable nature of old age ought to accord it or Beckett's fittingly nuanced take on it. For all the gloominess of his vision, it is not uncommon to find Beckett 'dwelling almost lovingly on the tropes of ageing': Barry 
rightly notes that, in his later work at least, 'he puts old age, or at least its associated attitudes and conditions, centre stage' $(2016,212,207)$.

As Beckett's oeuvre evolves, we can see old age first gaining prominence and then becoming a linchpin: though initially figuring somewhat incidentally, it eventually becomes all-encompassing, to the point where it becomes the norm - to the point where Beckett seems to suggest that, in an important sense, we are born old (Schenck, 2016, 299). This is more than a playful aphorism - the implication here is that old age stands for the state of simply being human. Simone de Beauvoir had the percipience to establish that connection in Beckett's work back in 1970, in La Vieillesse (1970, 226). Barry reinforces that link by observing that, in Beckett's oeuvre, 'the condition associated with old age is seen simply as an amplification of the general one' $(2015,140)$.

The seeds of this notion can be seen germinating beneath the surface of his early radio works, and All That Fall is a perfect example of this. This article sets out to explore the conceptual symbiosis between the thematisation of ageing and agedness and the radiogenic (because so inherently congenial to the medium) problematisation of embodiment as manifest in All That Fall. It will also be shown that its particular thematisation of old age is fundamentally linked to the very medium for which it was written, by dint of radio's complex relationship with corporeality and, by extension, embodiment.

\section{On the aptness of somatic readings of agedness in radio art}

Thinking about embodiment and old age in conjunction is not particularly uncommon, but it is often done in ways that deprecate both elements of the equation and therefore are too reductive to be of interest for the purposes of this article. The widespread perception of the aged body as little more than a harbinger of terrible things can be traced back to the unapologetically dualist tendency of Western philosophy, but even 'philosophers of lived time' such as Husserl and Heidegger fall short of addressing 'the Cartesian negligence of the constitutive importance of the body', which is upheld by Merleau-Ponty, and thus fail to include senescing in an account of ageing without allowing it to simply stand for ageing (Baars, 2012, 147, 162). The strange absence of old age in canonical phenomenological thought, namely in the works of Heidegger and, more surprisingly still, Merleau-Ponty, is also duly noted by Barry $(2015,135)$.

The problem is more intractable than it seems. Old age can hardly be dissociated from the body - 'Ageing is - if nothing else - an embodied experience' (Barry, 2015, 136) - and the ageing person's increasing awareness of this fact is described by Drew Leder as the 'dys- 
appearance' of the body, that is, its salience through what is commonly perceived to be mere dysfunction (1990, 89-90). However, reactions to the 'dys-appearing' body tend to be defined by rejection, which materialises into perceptions of the body as 'other', as a 'bad self', or as a 'betrayer of the self' (Gilleard and Higgs, 2018, 7-8), and this is what philosophers such as Beauvoir, certainly 'no Cartesian', mean when they suggest that 'the desire to disown the body - the Cartesian temptation - becomes increasingly strong with age' (Davis, 2006, 46). And it does not take much of an imaginative leap to see how the artistic depiction of such fantasies of non-embodiment are ideally suited for the least bodily of all performative media - in the mid-twentieth century, that meant radio.

Before launching into a close reading of the aged body in All That Fall (1957), then, it is worth considering the theoretical and cultural baggage of the concept of corporeality in the specific context of radio art and the dualist proclivities often associated with it. After all, radio is frequently deemed 'blind', 'inward-looking', and 'disembodied' - all traits that would seem to reveal a singular readiness to accommodate the 'contained', 'bodiless', and 'solipsistic' voice that is 'the Cartesian voice of Reason', the 'inner voice' of Western metaphysics that stands for a purified intellect and therefore aspires to remain 'uncontaminated' by the body or the atmosphere (Dyson, 2009, 20-25). And, in fact, Beckett criticism proffers several examples of interpretations that are to a great extent complicit in this sort of thinking: as Ulrika Maude remarks, '[t]he first wave of Beckett scholarship, characterized by the works of critics such as Hugh Kenner and Esslin, read Beckett as a transcendental writer who subscribed to a Cartesian dualism' $(2009,1)$, an approach that is especially entrenched in the discussion of his radio works (Connor, 2009, 275).

The question is, does Beckett's well-established interest in what one may term methodological scepticism, and the richness of his engagement with the idea of embodiment, prepare the ground for a dualist aesthetics of non-embodiment? That is to ask, can nonembodiment be said to represent not only a means to an end but actually the telos of his radio works? In a word, no: entertaining a thought need not entail one's acceptance of it, and dallying with Cartesian dualism is not tantamount to corroborating its veracity. When Beckett depicts traits and predicaments stereotypically associated with old age, plays with the concepts of non-embodiment and mind/body dualism, and shows the world through the hazy lenses of sensorial scepticism, he is merely using the medium of radio as 'as an experimental laboratory for composition' (McMullan, 2010, 77), and sensorial scepticism as a tool, the better to problematise conventional meanings of old age and fantasies of non-embodiment, without necessarily endorsing or rejecting any such aesthetics. 
But just as Leder warns us of how the pernicious 'kernel of truth' in the dualistic view leads us to instinctively accept it as true $(1990,107)$, there is something to be said about the early critics' claims that Beckett is in thrall to notions that hark back to Cartesian dualism, which are not as easily dismissed as they perhaps would seem to be. It would be sensible to dispassionately consider the merits of such interpretations without losing sight of their shortcomings, and indeed an important parallel might be discerned between the perceived disembodying propensity of the medium of radio and the specific way in which the aged radio body is depicted in All That Fall. In the end, as we shall see, radiophonic corporeality is problematised in complex ways in this radio piece: it is simultaneously foregrounded and called into question - which ties in perfectly with the received notion of a prominent but resented corporeality in old age.

\section{'Oh, to be in atoms': on reluctant corporeality in All That Fall}

As Clas Zilliacus observes, All That Fall's verbal and geographical concreteness, large cast, and relatively eventful plot set it apart from most of the Beckett canon (1976, 30, 32). For these and other reasons, it is commonly accepted that 'Beckett's first radio play is also the most accessible one' (Frost, 2014, 254). This accessibility is partly explained by the pressures of the medium itself, which in turn testifies to the radiogenic nature of All That FallBeckett's famous medium intransigence (that is, his unwillingness to adapt his own works from one medium to another) is frequently cited in relation to this radio work (see for example Guralnick, 1996, x; Bloom, 2016, 148). That radiogeneity is exemplarily demonstrated by Bloom in her reading of Beckett's first radio piece as a work that is preoccupied with '[s]onic obsolescence' and that cannot be dissociated from having been 'conceived in the shadow of radio's apparent vanishing act' $(2016,128,133)$.

Such radiogeneity has often led critics to consider that All That Fall is mostly, if not solely, concerned with inner life, or what Murphy's eponymous character would have called 'the little world' (see for example Frost, 2014, 254, 257). This notion of radio art causing the head to become a 'mental theater' is frequently taken to its logical - if perhaps disputable conclusion, namely the idea that All That Fall is first and foremost defined by 'insubstantiality' (Campbell, 2009, 152, 150). This thesis is lent some credence by Emilie Morin's account of All That Fall's debt to acousmatics, what Pierre Schaeffer described as 'a noise that one hears without seeing the causes from which it originates' (Morin, 2014, 1-2). Morin argues that 'Schaeffer's reflection on acousmatics, in turn, shares important artistic and conceptual affinities with Beckett's utilizations of disembodied voices', whose 
'explorations of disembodiment' hinge on '[t]he ethereal nature of the recorded voice and the immateriality of the radiophonic body' $(2014,1,10)$.

A very different approach consists of emphasising how 'bulkily bodily' All That Fall is (Connor, 2009, 290). Porter, for example, writes at considerable length on the 'radiophonic body' in that radio piece (2010; see also 2016, chapter 6), even though he focuses more on themes such as 'sterility, paralysis, decay and death' $(2010,431)$ rather than old age, which is mentioned only in passing (e.g., 2010, 434). Porter comments on Maddy's 'surprising materiality and presence', which is conveyed both through language and sounds, that is to say both ekphrastically and by means of sound effects $(2010,431,438)$. Olga Beloborodova and Pim Verhulst too speak of 'Maddy's sprawling body', and of her 'continuous interaction with her environment', as evidence of the existence of a material outer reality $(2018,250)$. And Maude, an expert proponent of somatic readings of Beckett, draws attention to Beckett's masterful use of sound to emphasise embodiment and materiality, considering that 'All That Fall prioritises exteriority and matter over interiority', as attested, among other elements, by 'Beckett's almost obsessive insistence on corporeal sounds in the play' $(2009,48,49,53)$.

There is some truth to both stances, and we may begin by analysing the evidence that testifies to Maddy's aural corporeality, that is, the 'surprising materiality' of what is in effect a disembodied voice floating in the airwaves. In truth, corporeality is never really absent from the voice, since the latter moves 'from the interior to the exterior, carrying traces of the body into evanescent speech' (Dyson, 2009, 7), but All That Fall, in both production and performance, goes the extra mile to drive that point home. Dan's scathing, oft-cited jeer'Two hundred pounds of unhealthy fat!' - is vividly brought to life by the constant sound of Maddy's 'dragging feet' and the ludicrously lewd '[s]ounds of effort' when she is hoisted onto and extracted from Mr Slocum's vehicle (Beckett, 2006, 191, 172, 178; hereafter ATF). The voice acting is another important factor to take into consideration: in the $1957 \mathrm{BBC}$ broadcast, Maddy is strong-voiced, and Dan sounds positively aggressive at times. Maddy's staunch corporeality bursts through not only the actual radio work but also the text itself: her abrupt and overwhelming mood swings, exquisitely rendered in the original as well as later productions, are made explicit in the textual directions (for example, ATF, 176). The content of her utterances too is revealing of her worldliness: to mention only one example of this, in a single, characteristically earthly tirade, she uses the word 'celibates' as an insult, alludes to her 'heart and kidney trouble', and complains that the delay risks ruining her 'Saturday roast' $(A T F, 187)$. 
But it is not just Maddy who can be said to be invested with aural corporeality, one which is defined by frailty as much as by a perhaps unexpected vigour, or what Anna McMullan calls her 'carnivalesque energy' $(2010,74)$. Even interpretations of the maybe centenarian Dan as the embodiment of 'a diminishing selfhood' (Porter, 2010, 436), or as a helpless symbol of physical decay (White, 2009, 29, 17), are far from watertight. His assertiveness, which is punctured a couple of times by his forgetfulness, is manifest in the directions provided in the text as well as in the original and later radio productions; his visceral anxiety at finding himself 'confined' is telling $(A T F, 195)$, as is the ominous and oftquoted 'Nip some young doom in the bud' line $(A T F, 191)$, which is itself indicative of a rapacious will (in its Schopenhauerian sense of blind driving force) and thus hardly compatible with notions of 'diminishing selfhood'. Other instances that further lend some sort of material concreteness to the general soundscape of All That Fall include the sound of Christy welting his hinny and the scene of domestic violence overheard by the older couple, caused, Maddy tells her husband, by the fact that Mrs Tully's 'poor husband is in constant pain and beats her unmercifully' $(A T F, 173,193)$. These incidents, among others, chime with Maude's view that the speaking characters' 'absent bodies' actually 'repeatedly find their way into All That Fall', thus buttressing those characters' claim to 'situatedness and facticity' $(2009,52,56)$.

Part of the joy in studying intricate works like this, however, is the wealth and variety of plausible interpretations that can spring from it. Let us again consider those two minor episodes. Mrs Tully's cries are clear markers of pain, but they are not accompanied by any sound suggestive of a physical struggle; they come across more like anguished lamentations echoing in the twilight, especially in the 2006 RTÉ production. And when the hinny is welted, the sound always makes its way to the radio productions, as per Beckett's written instructions - but we do not hear the hinny react in any way. Before the welting, Maddy marvels at how '[s]he does not move a muscle' $(A T F, 173)$, and the listener is given no reason to believe that anything changes after it. These incidents, like resolute little glitches, seem to show an eerie disconnect between bodies and the putative stresses of the physical world, and thus threaten to play havoc with the characters' (even if merely aural) corporeality and the plausibility of the claim that they lead an embodied existence.

The character that perhaps best epitomises the overtures to or at the very least thematisation of dis- or non-embodiment in All That Fall is clearly Miss Fitt. She presents herself as a devout Protestant who in church is 'alone with her Maker', 'oblivious' to the point that she sees nothing and no one - even, rather conveniently, when the collection is 
taking place $(A T F, 182)$. She takes heed of no one, and no one takes heed of her - in a way, she muses, 'the truth is I am not there, Mrs Rooney, just not really there at all' $(A T F, 183)$. Her commitment to the material world is so tenuous that, '[1] eft to myself, with no one to check me, I would soon be flown ... home' $(A T F, 183)$. Other, more oblique instances of her affinity with non-embodiment include the idea of 'pure' music being contaminated by earthly words. Miss Fitt likes to hum her hymns, and when Maddy 'joins in with the words' Miss Fitt stops and loses all composure: 'MISS FITT: [Hysterically.] Stop it, Mrs Rooney, stop it, or I'll drop you!' (ATF, 184).

That being said, even the ageing couple's own corporeality not only 'dys-appears' but threatens to actually disappear through sensorial erosion and failing lifeforce. Dan's often cited lamentation concerning his ill health $(A T F, 191-192)$ leads him to conclude that the loss of his sight 'was a great fillip', and that he 'might pant on to be a hundred' should he also 'go deaf and dumb' $(A T F, 192)$. And Maddy herself, her body 'both a material encumbrance which weights every step and a protean material which shifts its shape to match her affective and psychic state' (McMullan, 2010, 70), is not substantially better: she has just re-emerged from a long stay at the hospital, declares herself to not be 'half alive nor anything approaching it', and reports feeling 'very cold and weak' and 'very cold and faint' towards the end of the radio piece $(A T F, 175,193,194)$. This important sense of disintegration as opposed to sudden obliteration is reinforced when she justifies her venturing outdoors, which she dramatically describes as 'suicide', by being a lesser evil than the 'lingering dissolution' that is 'to be at home' $(A T F, 175)$.

Even more intriguingly, their corporeality is not only precarious, it is also often reluctant, as demonstrated by Dan's fleeting mention of his wish 'to be buried alive' and Maddy's recurrent protests against bodily existence (ATF, 194; 175, 177, 180-181). Their hankering after an aethereal state (be it dead, alive, or anywhere in between) is given powerful expression in the most well-known exploration of non-embodiment in All That Fall, namely Maddy's melancholy speech on solitude, which is brimming with aural antinomies:

MRS ROONEY: All is still. No living soul in sight. There is no one to ask. The world is feeding. The wind - [Brief wind. $]$ - scarcely stirs the leaves and the birds - [Brief chirp.] - are tired singing. The cows - [Brief moo.] - and sheep - [Brief baa.] ruminate in silence. The dogs - [Brief bark. $]$ - are hushed and the hens - [Brief cackle.] - sprawl torpid in the dust. We are alone. There is no one to ask. [Silence.] $(A T F, 192)$ 
Maddy's despondent last sentence is clearly meant to be a grand statement that is illustrated, if elliptically, by her figurative meditation on the farmyard animals that surround her: we hear token aural signs of each animal that she evokes, only for her to immediately undermine their stability as signifiers, claiming that the beings they refer to issue no such sounds (and indeed cannot possibly do so, as is half-implied of the hens who 'sprawl torpid in the dust'). The implication of this, of course, is that such a pseudo-presence might also apply to the colourful roster of characters whose existence the listener had hitherto been led to simply presume.

Embodiment in All That Fall, like more or less everything else in Beckett's oeuvre, is clearly not a straightforward affair. It is exceedingly hard for the listener to settle for any one interpretation - embodied or disembodied, interior or material - because All That Fall repeatedly proves itself to be as amenable to both as it is resolutely opposed to a total identification with either. If corporeality is already a debatable notion when it comes to radio art in general, we have seen that somewhat paradoxically (given its enhanced concreteness) it is just as rickety in All That Fall. The precariousness of these radio bodies, allied to the unsettling permeability between the internal and the external that defines this radio piece (McMullan, 2010, 74), restricts the applicability of embodied readings: Maddy and Dan may be said to possess an embodied mind perhaps only in the rather peculiar sense that their bodies and minds are similarly infirm.

What is extremely interesting for the purposes of this article is that their state of infirmity seems to be depicted as a natural one - that is, it is the norm. This is suggested, for example, by the crumbling environment in which Maddy and Dan operate - and which in an important way complements them. Decay prevails, and the agedness of the protagonists is habitually interpreted as merely one of its many markers, but that is a disservice to its complexity and importance, as it should by all rights be considered a key thematic nub of All That Fall. One of the main goals of this article, then, is to redress that oversight. The remainder of this essay will be dedicated to the thematisation of old age in this radio piece and the different angles from which it can be approached; the analysis of that theme will be guided by the notions of disengagement, irremediable regret, and the 'réveil mortel'.

\section{Beyond mortality and sterility: old age and its many guises}

It is meaningful and fitting that a duplicate image of a forlorn old woman listening to Schubert's dirge should bookend All That Fall. In its themes and general tone, the radio piece 
is as bleak as it is complex. Understandably, Beckett commentators have always deemed death a pivotal subject of this radio work, and the more obvious and significant illustrations of this have been extensively quoted in Beckett criticism. Death is virtually omnipresent, present even in the textual directions themselves: murmurs, music, and steps are all supposed to 'die' $(A T F, 172,197,199)$. As Zilliacus writes, All That Fall 'is known as a play which relentlessly muses upon barrenness, decay, decline and death' $(1999,295)$, and adds that it was actually 'gradually enriched and enlivened' $(1976,31)$ as it rendered more palatable the unalloyed gloom of earlier manuscripts $(1999,296)$. Still, it remains a work teeming with 'untimely deaths', 'constant pain', 'sterility', and even 'damnation' (Zilliacus, 1976, 38, 40, 46; see also Porter, 2010, 431).

Having said that, and as Zilliacus's dismal list makes clear, this radio piece is as much about mortality and finitude as it is about infertility, sterility, and the impossibility of creation (see also McMullan, 2010, 71). And what better way is there to call to mind received notions of both finitude and barrenness than through the thematisation of old age? That is precisely what Beckett does in this radio work and elsewhere, but critics tend to either overlook or downplay this connection. Often, the presence of the topos of old age in All That Fall is parenthetically alluded to (see for example Van Laan, 1985, 39; Guralnick, 1996, 89; Bloom, $2016,132)$, but no discussion of the symbolic use of that trope, or of the meticulous way in which it is woven into the fabric of the radio work, ensues. Whenever old age in All That Fall is indeed taken into account in any detail, however, it is usually imbued with catastrophic overtones, the whole point of depicting old age, the argument goes, being to make the imminent prospect of death more agreeable (see for example Esslin, 2014, 53; White, 2009, 29).

This is a legitimate interpretation, but certainly not the only possible one. Its polar opposite is hardly defensible, since clearly Beckett does not set out to dispel such thoroughly negative notions. Instead, it could be argued that Beckett is happy to use those received associations towards his own ends, that is, the depiction of life in general, and not merely of a dreaded, future, impossibly distant 'stage' of it. The normative associations of old age with regret and linear (and detrimental) progression - evoked in the only quotation, slightly disguised by imperfect recall, to overtly figure in All That Fall besides the biblical passage that gives the work its title: "Sigh out a something something tale of things, Done long ago and ill done" $(A T F, 174)$, which harks back to John Ford's play The Lover's Melancholy - are part and parcel of a chronometric view of ageing, which represents a very valid way of reading the thematisation of old age in All That Fall. The chronometric paradigm makes itself 
felt even in such trivial details as Maddy's scrupulous timekeeping and Dan's repeated wish to know exactly how old he is, to name only a couple of examples $(A T F, 188,192)$. Also, it finds expression in Dan's love for conventional narratives, noticeable in the relish with which he imparts his 'relation' $(A T F, 192-195)$ - which, interestingly, he begins by vouching that the train left its station 'on the tick of time', an assurance that puzzles Maddy, given his blindness $(A T F, 192)$.

In addition, Maddy's uncharacteristically detailed life story, and Dan's penchant for narratives, history, and counting - 'Not count! One of the few satisfactions in life!' (ATF, 190; see also 188, 189, 193) - synergise well with the linear progression of All That Fall. Maddy's itinerary (A-B-A) and the incidents that function as bookends, such as Schubert's music and the sighting of the laburnum, might give an illusion of circularity, but the steady deterioration of the weather gives the lie to that interpretation: the day begins by being described as nice, even 'divine', but soon the listener hears several lamentations to the effect that ' $[\mathrm{t}]$ he best of the day is over' $(A T F, 181)$, and in fact ends with a ' $[t]$ empest of wind and rain' $(A T F, 199)$.

The idea of a threshold beyond which lies only decline is crucial, and in this context 'disengagement theory'can have its value as a hermeneutical tool. First formulated in 1960, disengagement theory grew out a study which set out to challenge the widely-held notion 'that society withdraws from the older person, leaving him stranded'; instead, the alternative hypothesis put forward was that 'the individual cooperates in a process of disengagement which takes place between himself and society' (Cumming et al, 1960, 23, emphasis added). 'The result of the disengaging process', the researchers who articulate the findings of this study conclude, 'is a more self-centered and idiosyncratic style of behavior among the ambulatory aged' (Cumming et al, 1960, 35).

Dan, in particular, is a paradigm of disengagement, being an aged individual who realises that it is time to cut the tether that, however loosely, has been tying him to society. The first sign of this comes when Dan announces that he wants to retire $(A T F, 190)$. Crucially, however, disengagement is often a mutual process (Fry, 2009, 512; Moody, 2006, 8), even if more often than not it is initiated by society, as is the case with Dan: 'Business, old man, I said, retire from business, it has retired from you' $(A T F, 193)$. Yet it is plain that he looks forward to it: 'Trudge this hellish road for the last time. Sit at home on the remnants of my bottom counting the hours - till the next meal. [Pause.] The very thought puts life in me! Forward, before it dies!' $(A T F, 190)$. A more sceptical listener might think Dan has been compelled to retire by a business that 'has retired from him' and now merely rationalises it, 
but in his case the wish appears to be genuine: all he wants is to 'hasten home and sit before the fire. We shall draw the blinds' $(A T F, 189)$. Everything about Dan - his avarice, his plans to retire, his longing for the cosy comfort of home and the blocking out of the outside world bespeaks self-containment and self-contentment; society no longer has a meaningful role to play in his life, intersubjectivity is not deemed worth all the trouble it brings about, and his ageist, potentially murderous contempt for children is the culmination of that anti-social mindset.

This, in essence, is a yearning for Murphy's 'little world' - which, the knowing reader will recall, was in Beckett's 1938 novel the sole preserve of an old man, Mr Endon. What is fascinating about the little world's would-be tenant that we encounter in All That Fall is how amenable his fantasy of solipsistic bliss is to both the idea of disengagement in old age and to some of the most widely-held conceptions of radio itself, the medium where all worlds are 'mental inventions' (Guralnick, 1996, 109), where the 'precarious suspension between existence and non-existence' reigns supreme (Kalb, 1994, 129), where the distinction between internal and external reality is blurred (Zilliacus, 1976, 81; McMullan, 2010, 68). This seamless bringing together of the theme of old age and the medium of radio is a perfect example of how Beckett instrumentalises their received associations in a positive feedback loop.

But the chronometric perspective is not the only one that yields productive readings. One example of a relevant non-chronometric way of thinking about old age is 'irremediable regret', whereby regret comes to be seen 'as no longer remediable, not even indirectly, not even aspirationally' (Cowley, 2017, 192). And indeed Maddy can gainfully be read in view of the 'lived time' notion that old age is a time of reflection on past errors - or, more forcefully put, that 'irremediable regret', more than any arbitrary line in the sands of time, can be said to establish her aged status. Her backstory (a ponderous Protestant Irish woman in her seventies who lost her little girl Minnie forty or fifty years ago and was recently bedridden due to ill-health) is indeed more fleshed out than readers and listeners of Beckett are used to, and this vivid insight into her past, along with her decision to quote Ford's melancholy lines, further reinforces the idea that Maddy is laden with and even partly defined by regret.

Another intriguing pathway towards an understanding of old age in terms of lived time in All That Fall is the idea of the 'réveil mortel'. The réveil mortel is, according to Charles Du Bos, the moment in which one's finitude truly sinks in (1946, 173); Christopher Cowley considers this life-changing realisation to be another possible non-chronometric way 
of defining old age $(2017,191)$. Two such epiphanies occur in quick succession. The first, more prosaic one hits Mr Slocum, who seems to take his failure to start the engine of his car a bit too much to heart. Upon being asked what he is doing, he languidly replies: 'Gazing straight before me, Mrs Rooney, through the windscreen, into the void' (ATF, 178). Maddy begs him to drive off, but he demurs, having been rather surprisingly called on by the spectre of the réveil mortel: '[Dreamily.] All morning she went like a dream and now she is dead' $(A T F, 178)$. The gloom is quickly lifted, as he manages to start the car - ironically, thanks to his decision to 'choke her' $(A T F, 178)$. During the ride, they run over a hen. Maddy is distraught:

What a death! One minute picking happy at the dung, on the road, in the sun, with now and then a dust bath, and then - bang! - all her troubles over. [Pause.] All the laying and the hatching. [Pause.] Just one great squawk and then ... peace. [Pause.] They would have slit her weasand in any case. $(A T F, 179)$

Here again the ponderousness of the insight is immediately undercut by a morbidly flippant remark. Beckett, as was his wont, gives his characters just enough self-awareness to allow his readers and listeners to divine the presence of the grim motif of finitude, but no more than that, lest his aged puppets foolishly aspire to the status of tragic heroes.

Ultimately, what we see here is a partial disavowal of the fantasies of nonembodiment so intimately linked to ageing and so amenable to be expressed, with something of an ironic twist, through an aural medium like radio. It is as though only the réveil mortel, as an insight attained by a vicarious understanding of finitude (through the failing engine and the dead hen), reveals the logical conclusion of such fantasies - the actual cessation of being, as opposed to some form of blissfully non-material subexistence. Given a choice between a hopeful flight of fancy and the sober awareness of its fancifulness, Maddy supresses the latter and holds on to the former. Indeed, as a rule, any given person, young or old, will disregard that bleak insight. But disregarding something does not make it go away; the knowledge is there, twinkling from a dark recess of the mind of anyone who spares as much as a thought to the omnipresence of death and its implications for the self; in that vital, 'lived-time' sense, any such person can be said to be old.

Already in All That Fall, then, we see how the topos of old age starts to become inextricably woven into the fabric of Beckett's artistic tapestry, so much so that it is more or less taken for granted; from a certain point (not far from this radio piece), the reader familiar 
with Beckett begins to assume by default that the protagonist of a given later work is aged. In his future attempts to create radiophonic (and radiogenic) art, Beckett's grappling with the enigma of embodiment (in conjunction with its phantasmagorical Doppelgänger, disembodiment, and its abstraction ad nihilum, non-embodiment) caused his thematisation of old age in radio art to take on new hues - and a heightened, more explicit significance - in works like Embers and Words and Music. Old age ceases to be a theme; it goes beyond that and becomes a given (Schenck, 2016, 299-300); from an outwardly expendable expedient in the form of pitiful pantomime, old age becomes a symbol of the common lot (Hubert, 2005, 45-47).

Teasing apart the ways in which corporeality is both foregrounded and problematised in All That Fall through a number of radiogenic techniques provides an important conceptual framework for a better understanding of its rich thematisation of old age. For Beckett, it seems, there is an insoluble link between being human and being old, and the formal and thematic characteristics of radio, with the unique possibilities to problematise corporeality it affords, played a critical role in shaping that proposition. 


\section{Bibliography}

Adelman, Gary (2005), 'Old Age and Beckett: A Partial Autobiography', New England Review, 26:3, pp. 138-148.

Baars, Jan (2012), Aging and the Art of Living, Baltimore: Johns Hopkins University Press.

Barry, Elizabeth (2015), 'The Ageing Body', in David Hillman and Ulrika Maude (eds), The Cambridge Companion to the Body in Literature, Cambridge: Cambridge University Press, pp. 132-148.

Barry, Elizabeth (2016), 'Samuel Beckett and the Contingency of Old Age', Samuel Beckett Today / Aujourd'hui, 28:1, pp. 205-217.

Beauvoir, Simone de (1970), La Vieillesse, Paris: Gallimard.

Beckett, Samuel (2006), The Complete Dramatic Works, London: Faber \& Faber.

Beloborodova, Olga and Pim Verhulst (2018), 'Broadcasting the Mind: Extended Cognition in Beckett's Radio Plays', in Olga Beloborodova, Dirk Van Hulle, and Pim Verhulst (eds), Beckett and Modernism, London: Palgrave Macmillan, pp. 239-257.

Bloom, Emily C. (2016), The Wireless Past: Anglo-Irish Writers and the BBC, 1931-1968, Oxford: Oxford University Press.

Campbell, Julie (2009), "“A Voice Comes to One in the Dark. Imagine”: Radio, the Listener, and the Dark Comedy of All That Fall', in Steven Barfield, Matthew Feldman, and Philip Tew (eds), Beckett and Death, London: Continuum, pp. 147-168.

Connor, Steven (2009), 'I Switch Off: Beckett and the Ordeals of Radio', in Debra Rae Cohen, Michael Coyle, and Jane Lewty (eds), Broadcasting Modernism, Gainesville: University Press of Florida, pp. 274-293.

Cowley, Christopher (2016), 'Coming to Terms with Old Age - and Death', in Geoffrey Scarre (ed.), The Palgrave Handbook of the Philosophy of Aging, London: Palgrave Macmillan, pp. 187-206.

Cumming, Elaine, Lois R. Dean, David S. Newell, and Isabel McCaffrey (1960), 'Disengagement: A Tentative Theory of Aging', Sociometry, 23:1, pp. 23-35.

Davis, Oliver (2006), Age Rage and Going Gently: Stories of the Senescent Subject in Twentieth-Century French Writing, Amsterdam: Faux Titre.

Du Bos, Charles (1946), Grandeur et Misère de Benjamin Constant, Paris: Corrêa.

Dyson, Frances (2009), Sounding New Media: Immersion and Embodiment in the Arts and Culture, Berkeley, CA: University of California Press.

Esslin, Martin [1961] (2014), The Theatre of the Absurd, London: Bloomsbury.

Frost, Everett C. (2014), “The Sound Is Enough": Beckett's Radio Plays', in S. E. Gontarski (ed.), The Edinburgh Companion to Samuel Beckett and the Arts, Edinburgh:

Edinburgh University Press, pp. 251-265.

Fry, Christine L. (2009) 'Out of the Armchair and Off the Veranda: Anthropological Theories and the Experiences of Aging', in L. Vern Bengtson, Daphna Gans, Norella M. Putney, and Merril Silverstein (eds), Handbook of Theories of Aging, second edition, New York: Springer, 499515.

Gilleard, Chris (2016), 'Old Age and Samuel Beckett's Late Works', Age, Culture, Humanities 3.

Gilleard, Chris and Paul Higgs (2018), 'Unacknowledged Distinctions: Corporeality Versus Embodiment in Later Life', Journal of Aging Studies 45, pp. 5-10.

Groninger, Hunter and Marcia Day Childress (2007), 'Samuel Beckett's Rockaby: Dramatizing the Plight of the Solitary Elderly at Life's End', Perspectives in Biology and Medicine, 50:2, pp. 260-275.

Guralnick, Elissa S. (1996), Sight Unseen: Beckett, Pinter, Stoppard, and Other Contemporary Dramatists on Radio, Athens: Ohio University Press. 
Hubert, Marie-Claude (2015), 'Beckett : un monde de vieillards', Recherches \& Travaux, 86, pp. 45-53.

Kennedy, Seán (2018), 'Introduction: (Dis)Embodied Beckett Studies?', Journal of Beckett Studies, 27:1, pp. 1-4.

Leder, Drew (1990), The Absent Body, Chicago: University of Chicago Press.

Maude, Ulrika (2009), Beckett, Technology and the Body, Cambridge: Cambridge University Press.

McMullan, Anna (2010), Performing Embodiment in Samuel Beckett's Drama, New York: Routledge.

Moody, Harry R (2006), Aging: Concepts and Controversies, fifth edition, Thousand Oaks: Pine Forge.

Morin, Emilie (2014), 'Beckett's Speaking Machines: Sound, Radiophonics and Acousmatics', Modernism/Modernity 21:1, pp. 1-24.

Porter, Jeff (2010), 'Beckett and the Radiophonic Body: Beckett and the BBC', Modern Drama, 53:4, pp. 431-446.

Porter, Jeff (2016), Lost Sound, The Forgotten Art of Radio Storytelling, Chapell Hill: University of North Carolina Press.

Schenck, Cécile (2016), 'Vieilles gens, jeune danse', Samuel Beckett Today / Aujourd'hui, 28, pp. 299-311.

Van Laan, Thomas F. (1985), 'All That Fall as "a Play for Radio"', Modern Drama, 28:1, pp. 38-47.

White, Kathryn (2009), Beckett and Decay, London: Continuum.

Zilliacus, Clas (1976), Beckett and Broadcasting: A Study of the Works of Samuel Beckett for and in Radio and Television, Åbo: Åbo Akademi.

Zilliacus, Clas (1999), 'All That Fall and Radio Language', in Louis Oppenheim (ed.), Samuel Beckett and the Arts: Music, Visual Arts, and Non-Print Media, New York: Garland, pp. 295-310. 